\title{
Artelogie
}

Recherche sur les arts, le patrimoine et la littérature de l'Amérique latine

2 | 2012

Mexique : espace urbain et résistances artistiques et littéraires face à la « ville générique »

\section{Arte público. Cuatro décadas de transformación de la Ciudad de México}

Gonzalo Ortega

\section{OpenEdition}

Journals

Edición electrónica

URL: https://journals.openedition.org/artelogie/7901

DOI: 10.4000/artelogie.7901

ISSN: $2115-6395$

Editor

Association ESCAL

Referencia electrónica

Gonzalo Ortega, «Arte público. Cuatro décadas de transformación de la Ciudad de México», Artelogie [En línea], 2 | 2012, Publicado el 21 enero 2012, consultado el 07 enero 2022. URL: http://

journals.openedition.org/artelogie/7901 ; DOI: https://doi.org/10.4000/artelogie.7901

Este documento fue generado automáticamente el 7 enero 2022.

Association ESCAL 


\title{
Arte público. Cuatro décadas de transformación de la Ciudad de México
}

\author{
Gonzalo Ortega
}

\section{Antecedentes}

1 Ciudad de México, donde los primeros asentamientos humanos se remontan a cientos de años en el pasado, cuando un grupo de personas provenientes de la mítica Aztlán (que se cree se encontraba en algún remoto lugar al norte) encontraron el símbolo que les indicaba el lugar designado por los dioses para establecerse: un águila devorando a una serpiente, posada sobre un nopal. La capital mexicana emblematiza la mexicanidad, al menos desde el símbolo narrado en ese mito, un símbolo que se extiende desde allí hacia todo el país y que, siendo justos, muy probablemente sólo enmarca la identidad particular de Tenochtitlán, de la Ciudad de México, del Distrito Federal, todos nombres para el mismo lugar. Hoy la ciudad está marcada por una serie de contradicciones y sinsentidos. El inicio de esa larga lista de contradicciones comienza con su situación geográfica, pues la primera traza urbana (la de los aztecas) integraba el ecosistema original -un lago en medio de enormes montañas- con sus calzadas y sus ingeniosos sistemas constructivos. Esa visionaria ciudad, con sus chinampas y trajineras, fue modificada drásticamente después de la caída del imperio a manos del ejército español. El agua del imponente lago fue drenada y las construcciones de piedra demolidas. Usos y costumbres cortados de tajo.

2 Sobre las contradicciones de la ciudad mucho se ha escrito, mucho se ha dicho. Y a veces suena ya a cliché, uno demasiado sobado para quienes vivimos aquí. Nos lo han repetido hasta el cansancio, desde la escuela primaria en la clase de historia: que lo que hoy somos es resultado del choque de dos culturas. Dos identidades, la española y la mexicana, que se han amado y odiado desde el inicio, mezclándose, hibridándose, y de alguna manera conservando cada una su independencia. Una ciudad, un país que ha 
experimentado más de cinco siglos de diversos intereses en conflicto, de sometimiento a los débiles y pobres, del ejercicio de poder que impone los intereses de unos sobre los derechos de otros. Al leer estas líneas queda claro que describen al México de hoy, pero también al de hace siglos; continúan definiéndonos como si nos hubiéramos congelado en el tiempo. Pero también está la otra cara de la moneda, pues la ciudad ha sido siempre el recipiente de incansables manifestaciones culturales, literarias y artísticas. Hoy en día, dicen algunos, la ciudad más grande del mundo (por sus dimensiones), o la ciudad con más museos, comentan otros. Ignoro si esto sea vedad o una invención, como muchas de las cosas que a los mexicanos nos gusta creer.

Definitivamente cada ciudad cuenta con características especiales que la hacen singular. La Ciudad de México es compleja, y lo es también el pensamiento de sus habitantes. Los artistas no se quedan atrás; por el contrario, se han manifestado históricamente de manera crítica y eficaz.

\section{Un parteaguas histórico}

Como un momento inicial para esta reflexión me gustaría recordar la situación sociopolítica que se vivía en el año 1968. Con motivo de las olimpiadas que se celebraron ese año se invitó a artistas de todo el mundo a contribuir con esculturas monumentales que se integrarían a la así llamada Ruta de la Amistad. Contraparte "cultural" al acontecimiento deportivo, 19 grandes figuras de concreto fueron colocadas a lo largo de la avenida Periférico, al sur de la ciudad, abarcando un total de aproximadamente 17 kilómetros. El artífice de esta iniciativa fue el reconocido artista alemán radicado en México Mathias Goeritz, quien contó con la ayuda del arquitecto Pedro Ramírez Vázquez para su realización. Indudablemente este proyecto se convirtió en uno de los momentos más relevantes del ámbito cultural del país. Pudiera decirse que la ciudad no sería la misma sin su paseo escultórico. La Ruta de la Amistad fue una celebración y el símbolo de una ciudad en la que se posaron los ojos del mundo entero. La lógica de su planteamiento y sus formas responden al lenguaje de la internacionalidad, transmiten un mensaje de paz muy acorde con la ideología olímpica.

Sin embargo, ese mismo año, el 2 de octubre, la Ciudad de México se convertiría también en el escenario de uno de los acontecimientos más trágicos de la historia reciente del país, cuando multitudes de estudiantes de educación media y superior salieron a las calles para manifestar sus diferencias de opinión ante motivos diversos, como el cuestionamiento de valores tradicionales, el ejercicio del poder político y la muy restringida libertad de expresión. El movimiento de los estudiantes mexicanos coincidió con otros movimientos similares que tuvieron lugar ese mismo año en países como Estados Unidos, España, China y Checoslovaquia, y que en esencia perseguían la emancipación de la sociedad y la lucha contra todo tipo de injusticias de índole social, racial y política. 1968, el mismo año del festival de Woodstock y de la muerte de Martin Luther King, el suelo de la histórica plaza capitalina de las Tres Culturas en Tlatelolco se mojó con la sangre de un número indeterminado de jóvenes (algunas fuentes mencionan: 700 heridos y entre 150 y 300 muertos) brutalmente agredidos por el ejército mexicano.

6 Dos acontecimientos que marcan el destino del país: las olimpiadas y la masacre, antónimos; hechos que se contradicen hasta en el más mínimo aspecto y que ocurrieron bajo la torpeza del entonces presidente Gustavo Díaz Ordaz, quien no supo encontrar 
otra alternativa ante los riesgos que implicaba para su gobierno el movimiento estudiantil más que la represión brutal. Al gobierno mexicano no le convenía el escándalo internacional previo a los juegos que mancharía la prístina y gloriosa imagen del país hacia el extranjero. Pero de fondo el problema era mucho más complejo, pues significaba un riesgo latente a la hegemonía del poder del Partido Revolucionario Institucional; un proyecto político que en aquél entonces llevaba ya casi cuatro décadas de gobierno no interrumpido. Desde la ciega lógica del poder era necesario, e incluso justificado, acallar al movimiento estudiantil. Este hecho definió el futuro de la posibilidad de los mexicanos de expresar críticamente sus opiniones políticas en el espacio público. Lo define porque atemorizó a cualquiera que intentara algo similar, pues ponía en riesgo su propia vida. El efecto psicológico en la población fue muy dañino. La versión oficial minimizó el número de víctimas y satanizó a los estudiantes, al grado de alterar la visión de la sociedad sobre la legitimidad del movimiento, así como de la supuesta libertad de expresión. Personas que asistían a la universidad en aquél entonces narran cómo se vio afectada su imagen social, como si hubiese sido "malo" ser estudiantes; recuerdan su prisa por concluir sus carreras para dejar de serlo. El término "estudiante" era utilizado en aquél entonces peyorativamente. Esta contradicción encuentra su única explicación posible dentro de la manipulación de información de un gobierno dictatorial. Uno se pregunta: ¿No hubiera sido una mejor decisión política hacer caso omiso del movimiento, ignorarlo y reducir su impacto mediático, sobre todo si se piensa en el control absoluto del presidente sobre los medios de comunicación en aquélla época? La respuesta es un torpe "no", pues el hecho dio la oportunidad a Díaz Ordaz de enviar un mensaje contundente a la población: no estaba permitido ir en contra de su proyecto de gobierno.

7 La represión por una parte, y por otra el embrutecimiento de la sociedad motivado por medios de información que distraían la atención hacia contenidos triviales y de mala calidad (el monopolio informativo de Televisa), contribuyeron a la generación de un público maleable, obediente y desinteresado en interactuar en el espacio público. La represión de 1968 significó la destrucción del ámbito público, la total desconfianza en proyectos colectivos y, al mismo tiempo, la ilusión de una ciudad con proyección internacional: una escenificación fallida, pero que todos los capitalinos creyeron o se conformaron en seguir.

\section{Renovación del interés en el espacio público}

8 En 1970 se decide reformular los planes de estudio de la Escuela Nacional de Artes Plásticas de la UNAM, decisión motivada en parte por la notoria participación de alumnos de esta instancia universitaria en el movimiento del 68. Ante el ofrecimiento de la Sra. Dolores Olmedo Patiño de donar un terreno en el sur de la ciudad, en Xochimilco, la ENAP inauguró sus nuevas instalaciones en 1979. La decisión implicó el confinamiento de los artistas jóvenes, potencialmente peligrosos y abiertamente incómodos para el estado mexicano, a la periferia geográfica y simbólica. Esta decisión imposibilitó no únicamente la integración de proyectos artísticos a la vida de la ciudad, sino que en un sentido inverso anuló la posibilidad de que los artistas encontraran referencias importantes sobre la ciudad para la formulación de sus propuestas. La ENAP dejaría de jugar un rol importante en los procesos sociales de la capital y varias generaciones de jóvenes estudiantes de arte serían condenadas a una educación 
artística tradicional. El plan de estudios se enfocaba únicamente en cuestionamientos de índole formal y estética, muy importantes, aunque con una visión reducida del papel que había jugado el arte en los años 70 y desconocedor de su potencial.

Por aquélla época, e igualmente como consecuencia de los acontecimientos en Tlatelolco, surgieron varios grupos de artistas con un interés renovado en el espacio público, en la democratización de la sociedad y en la política, al igual que en el papel que el arte debía jugar dentro de todo ello. Sin embargo debe mencionarse que la influencia del movimiento estudiantil de años atrás es indirecta para esta generación, pues la mayoría de quienes pertenecieron a los Grupos eran niños o adolescentes en el 68; de manera que sería más adecuado afirmar que respondieron a un contexto político, social y artístico determinado por el contexto mexicano posterior a la matanza de Tlatelolco ${ }^{1}$. Algunos de "los Grupos" con mayor relevancia fueron: Germinal, Março, Mira, No Grupo, Peyote y la Compañía, Proceso Pentágono, Suma, Taller de Arte e Ideología (TAI), Tepito Arte Acá, Tetraedro, Taller de investigación Plástica (TIP), entre otros. Sus propuestas evidenciaban una inclinación hacia la experimentación con diversos materiales y técnicas. Sin embargo no se puede decir que todos los grupos compartían el interés en trabajar con temas políticos. Gran parte de las valiosas propuestas de los Grupos tuvo que ver con cuestionamientos sobre lenguaje y estética, lo que los llevó a incursionar en medios como el cine, grabación de audio, publicaciones y fotografía documental. Igualmente se les reconoce la búsqueda y diversificación de públicos, y la creación de espacios innovadores para la presentación de sus proyectos.

10 La herencia de los Grupos para el arte público de décadas posteriores en la Ciudad de México es irregular y diversa. El grupo Proceso Pentágono, por ejemplo, dejó sin duda su huella en el arte conceptual del país, especialmente en proyectos con tema político. De manera muy distinta el artista Sebastián, quien formó parte protagónica del grupo Tetraedro, después de la desintegración de ese colectivo desarrolló un concepto de escultura urbana apoyado en formas geométricas que poco tiene que ver con el contexto crítico y político de la ciudad y que, en muchas ocasiones, inserta figuras gratuitas y frívolas en entornos de distintas ciudades del país.

\section{La transformación de la ciudad y la inseguridad}

11 La evolución de la mirada artística sobre lo público no proviene únicamente de la reflexión sobre cuestiones formales, de lenguaje, estéticas, estrategias, etc., sino que responde también a la transformación física de la ciudad. El entorno urbano de la capital mexicana cambia constantemente, y con él la opinión crítica sobre su situación, la visión a futuro de proyectos de vialidad y vivienda, la noción sobre el uso de espacios de convivencia, la recuperación de su pasado, etc. La historia del espacio público de la Ciudad de México es sinónimo del comportamiento humano que le ha dado forma. Su ámbito es, más que un espacio físico, un proceso en el que el espacio dado se corresponde con figuras sociales que lo han transformado y continúan haciéndolo. Este proceso genera una gran cantidad de causalidades y efectos que merecen ser revisados con detenimiento si se quiere entender las manifestaciones artísticas en el espacio público de las últimas cuatro décadas.

12 La Ciudad de México de los años setenta, entreverada de ejes viales que diario modificaban su geografía tradicional al separar barrios vecinos, pero -y esto tiene su importancia-comunican entre sí los polos norte y sur, oriente y poniente, de la incorregible mancha urbana $a^{2}$. La de los 
años ochenta que, como consecuencia de una relativa mejora económica del país (aumento en el producto interno bruto, en contraposición a la inflación y a la deuda externa del país) aceleró la expansión de la población urbana en el Valle de México, misma que no ha podido ser controlada desde entonces (en diez años el índice delictivo aumentó más del $40 \%$ ). La ciudad de los años noventa, reflejo del entonces recién implementado modelo neoliberal y de una aparente estabilidad económica y social, que pronto se vería afectada nuevamente por elevados índices delictivos. Ésta fue la misma década en la que el PRD (Partido de la Revolución Democrática, centro-izquierda) ganó con gran ventaja el gobierno del Distrito Federal. La ciudad de la primera década del nuevo milenio, marcada por el cambio en la política del país a nivel federal, después de 70 años de la línea del PRI (Partido Revolucionario Institucional, centro-derecha) -que en realidad no resultó tan distinta a la del PAN (Partido de Acción nacional, derecha)-; una ciudad marcada por el populismo político y por la gran desigualdad social. Y finalmente la ciudad de hoy, con sus tropezados flujos de servicios, transporte y seguridad social, que repite momentos de su historia al haber comenzado a recibir multitudes de personas provenientes del interior del país que huyen de la guerra que inició el actual gobierno de Felipe Calderón contra el crimen organizado.

A pesar de que la ciudad no ha experimentado las terribles secuelas de la guerra contra el narcotráfico que han sufrido ciudades del norte del país como Tijuana, Ciudad Juárez o Monterrey, el problema de la inseguridad es muy notorio. El temor a ser asaltado o secuestrado por bandas de criminales ha cancelado por completo la posibilidad de disfrutar el espacio público. Igualmente la absoluta ausencia de un sistema de impartición de justicia -un aparato gubernamental completamente corrupto y sometido a intereses económicos dudosos-, ha desencadenado la desilusión general de los habitantes ante un proyecto social colectivo.

\section{Secuelas del descontrol y neoliberalismo}

La ausencia de control político en una ciudad como la capital mexicana tiene consecuencias muy notorias en la manera en la que sus habitantes la perciben y en cómo interactúan dentro de ella. Además, la imposibilidad del gobierno de implementar reglas (de tránsito o civilidad) que generen una mejor convivencia entre los ciudadanos, pudiera interpretarse como la apertura de un ámbito de libertad para que cada quien haga lo que quiera; pero por el contrario complica seriamente los ritmos de la ciudad y los habitantes padecen estrés, irritación y angustia. Un contexto sociourbano con estas características dista mucho de ser un espacio de libertad. Por lo tanto sería más acertado definir a ese contexto como uno en el que se ha ido perdiendo el control del espacio público, de manera proporcional a la irrupción de fuerzas ajenas a él: como la presencia excesiva de publicidad de todo tipo, imágenes que vorazmente se apropian de cualquier superficie urbana, campañas comerciales o gubernamentales que se pelean hasta el último centímetro.

Todos los días se ven proyectos e iniciativas políticas que pierden relevancia frente a los problemas cotidianos de los ciudadanos. Las consecuencias de este proceso de debilitamiento obligan al estado a abandonar, ceder o externalizar (por medio de outsourcing) sus funciones. Como consecuencia de lo anterior, estas funciones quedan a la deriva de las imprevisibles reglas del mercado y la competencia neoliberal ${ }^{3}$. La interacción de las personas en un contexto colectivo, antes atractivo, se degrada y al 
mismo tiempo se destruyen las bases de la solidaridad social. Los vínculos entre las personas son cada vez más frágiles o temporales debido a que se enfocan en las reglas del mercado, consumo y trabajo. Los individuos pierden cualquier deseo de convivencia $\mathrm{y}$, por el contrario, adquieren una actitud de competitividad destructiva.

Lo anterior, sumado a la transformación que se sufre en todo el mundo como consecuencia de la globalización y a la pérdida del poder de los gobiernos frente al ascenso de economías empresariales muy poderosas, ha generado un latente espacio de acción que, en el caso de la Ciudad de México, ha sido aprovechado poco por los artistas. La capital mexicana, a lo largo de las últimas cuatro décadas, ha sido el escenario intermitente de proyectos artísticos que, a manera de resistencia, han intentado devolverle al ámbito de la colectividad (calles, parques y plazas) su vitalidad $\mathrm{y}$ valor sociocultural. Algunos proyectos se han enfocado en la recuperación de espacios de interacción comunitaria; otros en la consigna política o en la realización de experimentos diversos de orden social.

\section{Momentos de incidencia efectiva del arte público}

17 Con lo anterior en mente, a continuación mencionaré algunos ejemplos -muy pocos-, de proyectos artísticos en el espacio urbano que han sido emblemáticos durante los últimos tiempos gracias a su poder de transformación, a su participación colectiva, a su postura crítica y a su visión. Dichos ejemplos ilustran el rol que, desde mi perspectiva personal, debe jugar el arte público en una ciudad como la capital mexicana. No pretendo invalidar otro tipo de aproximaciones al tema, sino resaltar aquéllas que han contribuido de manera eficaz a la construcción de lo público. Me es importante reconocer aquéllas iniciativas que han combatido la individualización de la sociedad, la esclavitud psicológica a la que orilla el consumo, la pérdida de tradiciones, al igual que la disolución de lo "público" en el espacio público4.

En 1990 tuvo lugar una acción artística en la colonia Roma de la Ciudad de México que sorprendió por su nivel de organización y por la claridad en el planteamiento de sus objetivos. Ante la amenaza de demolición de un edificio histórico ubicado en la esquina de las calles Álvaro Obregón y Orizaba, conocido como el Edificio Balmori, que supuestamente había sufrido daños estructurales serios en el terremoto de 1985, el colectivo Salón des Aztecas liderado por Aldo Flores movilizó a más de 100 artistas de generaciones diversas para tomar el inmueble y llamar así la atención sobre su valor histórico, haciendo concientes a la comunidad de vecinos, a autoridades y al público en general, del grave error en el que se caería si se procedía con el plan. Hoy en día el edificio se mantiene perfectamente restaurado y como un símbolo de ese barrio histórico de la ciudad.

Poco tiempo después, el artista belga radicado en México Francis Alÿs comenzó a destacarse gracias a una gran cantidad de acciones artísticas en el espacio público, cuyo objetivo central era reconsiderar lo poético como el punto de confluencia de una diversidad de formas de investigación y experiencia eminentemente políticas, en tanto replantean la noción de la ciudad como comunidad ${ }^{5}$. Sobresale un video documental de una caminata por el Centro Histórico en la que puede verse a Alÿs portando una pistola hasta que es detenido por policías. Esta acción real se exhibió paralelamente a un segundo video, grabado minutos después, y en el que el artista convenció a los mismos policías de 
"repetir" la escena (Re-enactments, 2000). Los proyectos de Alÿs cuestionan de manera muy efectiva la noción de realidad de la Ciudad de México.

Con una óptica distinta, el proyecto Mejor Vida Corp., iniciado en abril de 1998 por la artista Minerva Cuevas, es una corporación sin fines de lucro. M.V.C. crea, promueve y distribuye productos y servicios gratuitamente a nivel mundial. M.V.C. no discrimina a ninguna persona por su género, raza, religión, preferencias sexuales o estatus económico ${ }^{6}$. Esta iniciativa surgió de una serie de cuestionamientos a procesos económicos capitalistas. El proyecto se apoya en la gratuidad como dispositivo de intercambio, por lo que ofrece servicios como la expedición de cartas de recomendación para los fines que a los interesados convenga; códigos de barras con precios más económicos a los que ofrecen cadenas de supermercados (para ser sustituidos por los usuarios), donación de boletos del metro y de sobres postales con timbre incluido, etc.

21 El objetivo de trabajar con el tema de lo público no es desencadenar reacciones inesperadas dentro de situaciones cotidianas, ni el tropiezo o la interrupción de los ritmos de la ciudad, sino la planeación de iniciativas y actividades con una finalidad clara. Conformarse con la unificación de arte y vida al obtener respuestas poco calculadas o accidentales denota, desde mi opinión, una ingenuidad que debe ser trascendida. La cultura urbana, y su complejidad inherente, invitan a la revitalización y movilidad de personas con una visión adormecida del uso de sus espacios de convivencia.

El proceso de reactivación de lo social es complejo y requiere en ocasiones de un tipo de sensibilidad especial que únicamente se puede adquirir al haber vivido el tiempo suficiente en un lugar como para entender las dinámicas sociales de la comunidad con la que se quiera trabajar. Si no se cuenta con esta sensibilidad o con información básica sobre determinado contexto, uno corre el riesgo de proponer proyectos que no son más que ocurrencias, ideas al vuelo que no logran vincularse con el lugar en el que se presentan y con las personas que lo ocupan o lo transitan. Para brindar un poco de luz sobre las posibilidades reales del trabajo de artistas en el espacio público vale la pena recordar las ideas del filósofo y teórico de medios ruso Mikhail Bakhtin (Oriol, 1895 Moscú, 1975), quien consideraba que arte y vida son cosas muy distintas. Para él ambos conceptos no deben buscar su mutua identificación: es justamente esa diferencia enriquecedora, excesiva y productiva la que genera valor. El momento en el que se hace notoria esa diferencia es llamado por Bakhtin "evento". La acción (entendida aquí como intervención artística) es lo que él sugería como elemento fundamental para crear un evento, pues cuenta con un potencial semántico y genera una relación de significado en su interacción con el espacio en el que se presenta ${ }^{7}$.

23 La Ciudad de México invita a reflexionar sobre una gran cantidad de situaciones que merecen ser confrontadas o solucionadas y que lamentablemente se anquilosan en las mentes pasmadas de sus habitantes, aturdidos por el exceso de estímulos visuales a los que son sometidos en el entorno urbano. Como ya se mencionó antes, la inseguridad mantiene además a los capitalinos en un estado de estupor durante su rápido tránsito por la ciudad con el único objetivo de llegar a sus destinos (hogares, trabajos, comercios) y confinarse. Casi por definición son los artistas quienes, históricamente, han evidenciado situaciones dramáticas de sus entornos sociopolíticos. La capital mexicana ansía hoy este tipo de iniciativas y emite un grito sordo que invita a sus habitantes a trasladarse de su actual aislamiento a la interrelación, a depender de los otros para motivar procedimientos sociales, a ser inteligentes y lúcidos. La ciudad debe 
recuperar sus espacios perdidos, crear ámbitos nuevos para la colectividad y empujar las fronteras de su visión autocrítica. La sociedad y su espacio físico merecen su emancipación.

\section{BIBLIOGRAFÍA}

BAUMAN, Zygmunt. Flüchtige Zeiten. Leben in der Ungewissheit / Einleitung. Unerschrocken in die Brutstätte der Ungewissheiten, págs. 7-9. Hamburger Edition HIS Verlagses, 2008.

BAKHTIN, Mikhail M. Speech genres \& other late essays. Edited by McGee, Vern W; Emerson, Carly; Holquist, Michael. University of Texas Press, Austin. Texas, 2006.

BIESENBACH, Klaus. Mexico City: An Exhibition about the Exchange Rates of Bodies and Values. P.S.1 Contemporary Art Center, a MOMA afíliate. New York, 2002.

DEBROISE, Olivier. El dandy kitsch / La era de la discrepancia. Arte y cultura visual en México 1968-1997. Página 200. Museo Universitario de Ciencias y Arte, UNAM. México, 2007.

FINKELPEARL, Tom. Dialogues in Public Art. Massachusets Institute of Technology, 2001.

JONAS, Uwe \& SCHUMACHER, Anna. Öffentlicher Stadtraum: Wandel und Okkupation. http:// www.okkupation.com/theorie/link_1.htm.

KÖNIG, Hans-Joachim. Kleine Geschichte Lateinamerikas. Universal-Bibliothek, Reclam. Stuttgart, 2009.

LAZZARATO, Maurizio. Dialogism and Polyphony. http://stealingsouls.org/node/85

MEDINA, Cuauhtémoc. Francis Alÿs / The Collector. La era de la discrepancia. Arte y cultura visual en México 1968-1997. Página 398. Museo Universitario de Ciencias y Arte, UNAM. México, 2007.

SENNETT, Richard. The Fall of Public Man. W. W. Norton \& Company, Inc. New York, 1977, 1992.

VAN DER REE, Dieteke. Hat die Stadt ein Gedächtnis? Bemerkungen zu einer schwierigen Metapher. Kulturwissenschaftliche Stadtforschung: eine Bestandsaufnahme. Kokot, Waltraud; Hengartner, Thomas; Wildner, Kathrin. Berlin: D. Reimer, 2000.

VÁZQUEZ MANTECÓN, Álvaro. Los Grupos: una reconsideración / La era de la discrepancia. Arte y cultura visual en México 1968-1997. Página 194. Museo Universitario de Ciencias y Arte, UNAM. México, 2007.

\section{NOTAS}

1. Vázquez Mantecón, Álvaro. Los Grupos: una reconsideración / La era de la discrepancia. Arte y cultura visual en México 1968-1997. Página 194. Museo Universitario de Ciencias y Arte, UNAM. México, 2007.

2. Debroise, Olivier. El dandy kitsch / La era de la discrepancia. Arte y cultura visual en México 1968-1997. Página 200. Museo Universitario de Ciencias y Arte, UNAM. México, 2007. 
3. Bauman, Zygmunt. Flüchtige Zeiten. Leben in der Ungewissheit / Einleitung. Unerschrocken in die Brutstätte der Ungewissheiten, págs. 7-9. Hamburger Edition HIS Verlagses, 2008.

4. Jonas, Uwe \& Schumacher, Anna. Öffentlicher Stadtraum: Wandel und Okkupation. http:// www.okkupation.com/theorie/l...

5. Medina, Cuauhtémoc. Francis Alÿs / The Collector. La era de la discrepancia. Arte y cultura visual en México 1968-1997. Página 398. Museo Universitario de Ciencias y Arte, UNAM. México, 2007.

6. Descripción del proyecto tal y como aparece en la página: http://www.irational.org/mvc/ espano...

7. Lazzarato, Maurizio. Dialogism and Polyphony. http://stealingsouls.org/node/85

\section{RESÚMENES}

El texto aborda no únicamente la creación de proyectos de arte público en la Ciudad de México, sino también la radical transformación que han sufrido los espacios de la colectividad a lo largo de poco más de cuatro décadas. La ciudad ha cambiado, de ser un entorno virgen - susceptible de servir de escenario a críticas políticas y sociales -, a su situación actual, en la que cualquier propuesta artística en las calles debe competir con una excesiva presencia de anuncios y propagandas. La privatización del espacio publico y la descontrolada marea de publicidad ocasionan el embrutecimiento de los capitalinos.

Ce texte n'aborde pas uniquement la création de projets d'art public dans la ville de Mexico, mais il traite aussi de la transformation radicale qui a affecté les espaces de la collectivité durant les dernières quarante années. La ville a changé, d'un environnement vierge - susceptible d'être l'objet de critiques politiques et sociales -, à sa situation actuelle, où toute proposition artistique dans la rue doit affronter la présence excessive de l'affichage publicitaire et politique. En outre, la privatisation de l'espace public et la marée incontrôlée des publicités provoquent l'abrutissement des habitants de la capitale.

\section{ÍNDICE}

Palabras claves: Arte público, Ciudad de México, transformación, intervenciones artísticas, espacios de convivencia, espacios para la colectividad, proyectos artísticos de inserción social

\section{AUTOR \\ GONZALO ORTEGA}

Curador independiente, Ciudad de México 